\title{
O ESTADO COMO LOCUS PARA CONCRETIZAÇÃO DA IDEIA DE LIBERDADE EM HEGEL: CONSIDERAÇÕES A PARTIR DA OBRA FILOSOFIA DO DIREITO
}

\author{
Anna Paula Bagetti Zeifert \\ Pontifícia Universidade Católica do Rio Grande do Sul - PUC/RS - Brasil
}

Gabriel Maçalai

Centro Universitário de Maringá - UNICESUMAR/PR - Brasil

\begin{abstract}
Resumo
A discussão sobre a relação entre Estado e Religião não é algo novo. O debate é antigo, perpassa os séculos, impondo novos desafios para os estudiosos, principalmente para aqueles que buscam em suas construções teóricas estabelecer quais seriam os pressupostos para a construção de uma sociedade justa capaz de conviver pacificamente com as mais diversas doutrinas. Assim, o presente trabalho visa resgatar a teoria de Hegel sobre a conexão existente entre Estado e Religião, onde suas doutrinas se aproximam e em que momento divergem, bem como as questões relativas à liberdade. A análise partirá do parágrafo 270 da Obra Princípios da Filosofia do Direito de Hegel, no qual o autor levanta essa discussão e aponta quais seriam as condições para estabelecer uma certa harmonia entre as duas instituições afim de se criar um Estado da liberdade. Num segundo momento, o estudo fará uma análise mais pormenorizada da ideia da liberdade e como a mesma se realiza no direito no entender de Hegel.
\end{abstract}

Palavras-chave: Estado. Religião. Liberdade

Considerações hegelianas sobre a relação Estado e Religião e busca por um pensamento universal racional

Já no início do parágrafo 270 da obra Filosofia do Direito, Hegel (1997) demonstra toda a sua preocupação com a questão da necessidade de afastar a Religião do Estado na busca de uma certa cientificidade, haja visto que para Hegel a Religião não estaria vinculada de forma direita com as questões da realidade. ${ }^{1}$ Estaria ela sim, preocupada com a consolação

\footnotetext{
${ }^{1}$ Essa parece ser uma das suas inquietações e que aparece evidenciada em várias de suas obras. Assim, "[...] o Hegel da Fenomenologia do Espírito, da Ciência da Lógica, da Enciclopédia, da Filosofia do Direito, da
} 
nos momentos de injustiça e com formas de compensações diante de qualquer forma de opressão.

É nesse sentido, que Hegel (1997, p. 217), entende ser necessário o estabelecimento de conceitos para os termos Estado e Religião, de maneira a estabelecer uma melhor compreensão sobre os seus conteúdos. Para o autor, a Religião "é a verdade absoluta e, portanto, ao seu domínio pertence o grau mais elevado do sentimento, ou seja [...] intuição, sentimento, princípio de Deus como causa infinita [...]" Desse modo, a "Religião exige que tudo seja compreendido do seu ponto de vista e nela tenha confirmação, justificativa e certeza. Por outro lado, na busca pela conceituação do termo Estado, entende o filósofo que esse representa "as leis, bem como os deveres, e nesta dependência obtêm a soberana garantia e a mais elevada obrigação para a consciência."

\begin{abstract}
O Estado é a substância ética autoconsciente - a unificação do princípio da família e da sociedade civil; esta mesma unidade, que na família existe como sentimento do amor, é a sua essência; esta, porém, mediante o segundo princípio do querer que discerne e é por si ativo, recebe ao mesmo tempo a forma de universalidade conhecida, a qual, como as suas determinações que se desenrolam no saber, tem por conteúdo e fim absoluto a subjetividade que discerne; ou seja, quer por si tal racionalidade. (HEGEL. 1970, p. 131)
\end{abstract}

Para guiar a condutas dos homens, segundo Hegel (1997, p. 222) é necessário analisar as consequências advindas quando esse processo está sendo desenvolvido pela Religião. Essa, movida por questões subjetivas, estaria condicionada ao livre-arbítrio e as paixões, desconsiderando qualquer forma política que possa limitar a ação de um sentimento mais íntimo. Por outro lado, o Estado preocupa-se, de forma objetiva, com seus fins e busca concretizar seus princípios de maneira a promover a verdade. Seria missão do Estado, “[...] proteger e assegurar a vida, a propriedade e o livre-arbítrio de cada um, na medida em que isso não lesa a vida, a propriedade e o livre-arbítrio de outro. O Estado aparece então como meio para suprir as necessidades;" cabendo a Religião o elemento espiritual, a verdade de forma subjetiva (em si e para si).

Nesse sentido, ambos buscam apreender a verdade, mas cada um a sua maneira. Não haveria uma divergência quanto ao conteúdo, mas sim quanto à forma como essa verdade é dada. Para Hegel, importa aqui analisar como essa verdade será apreendida, de forma interna

Filosofia da Religião, da Filosofia da Estética, da História da Filosofia ou, ainda, o da Filosofia da História, é sempre o mesmo filósofo preocupado com a liberdade dos seres humanos. A sua filosofia desvela a emergência da consciência da liberdade, a qual é o fundamento de toda a ação política. Mas, por isso, segundo Hegel, deve haver a consolidação do desenvolvimento do princípio da liberdade, em especial, na religião. A religião que reconcilia, que religa, a religião em sua verdade, para Hegel, é tão somente a religião da liberdade. (KONZEN, 2014 , p.49, grifo do autor) 
(consciência moral), por cada indivíduo, ou exteriorizada e colocada diante das mais diversas leis e princípios do Estado. Esse é o ponto que para alguns demonstra a possibilidade de acordo ou de oposição entre ambas as doutrinas. (KONZEN, 2014)

No momento em que ambos buscam externalizar as sua doutrinas, podem haver divergências quanto ao conteúdo de cada uma, visto que uma estaria no campo da objetividade (Estado) e a outra no campo da subjetividades (Religião). Diante disso, no entender de Hegel (1997, p. 222-223), haveria uma supremacia da doutrina estatal com relação à doutrina religiosa. Isso é possível porque “o Estado conhece absolutamente os seus fins, adéqua-se a eles e os realiza com uma definida consciência segundo seus princípios." Por outro lado,

\footnotetext{
A religião é a relação com o absoluto na forma do sentimento, da imaginação e da crença e no centro dela, que contém tudo o que é, tudo o que existe torna-se um acidente que se evanesce. Se, quanto ao problema do estado, não nos desprendermos desta forma religiosa até o ponto de ela nos aparecer como o que determina essencialmente e lhe atribui valor, entãoo Estado, que é um organismo desenvolvido em partes diferenciadas e fixas, em leis e instituições, cai na hesitação, na incerteza e na perturbação.” (HEGEL, 1970, § 270, W. 7)
}

Para Hegel (apud KONZEN, 2014, p. 51), “o Estado sabe o que ele quer, e o sabe em sua universalidade, enquanto algo pensado; por causa disso, ele atua e age segundo fins conscientes, segundo princípios conhecidos e segundo leis que não são apenas em si." Segundo o referido autor, as ações do Estado "[...] se vinculam com as circunstâncias e as relações presentes, ele atua e age segundo o conhecimento determinado das mesmas.

Já na Religião, o conteúdo já é dado, "não é conhecido nem pelo pensamento nem pelo conceito. Por isso, a relação do indivíduo com esse objeto [verdade] é um dever fundamentado na autoridade." Nesse caso a liberdade apresenta-se como sentimento e crença. (HEGEL, 1997, p. 222-223)

Esse processo de interferência da Religião no campo exclusivo e de domínio do Estado pode levar consequentemente à imposição de uma doutrina moral e a supressão de toda a laicidade que deveria estar presente nessa instituição denominada Estado. Para Hegel (1997, p. 218), é possível que daí surja o chamado "fanatismo religioso que, tal como o político, leva a supressão de toda a organização política e de toda a ordem legal, enquanto limites restritivos e inadequados à infinitude do pensamento íntimo.”

\footnotetext{
Assim como se considerava irrisório abafar todo o ressentimento contra a tirania porque o oprimido encontraria consolo na religião, assim é preciso não esquecer que a religião pode assumir formas tais que conduzem à mais dura escravidão nas cadeias da superstição e à degradação do homem abaixo do animal [...] é preciso não
} 
falar da religião em geral e de que, muitas vezes, é necessário ganhar forças para lutar contra ela em alguns de seus aspectos e para defender os direitos da razão e da consciência de si. (HEGEL, 1970, § 270, W. 7)

Segundo Bourgeois (apud KONZEN, 2014, p. 52), a título de exemplo, utiliza-se a crítica de Hegel ao "Estado judaico como Estado religioso no qual os comandos de Deus têm lugar de Constituição política". Para tanto, no entender hegeliano, deveria haver uma separação entre a esfera estatal e a esfera religiosa. Caberia ao Estado tão somente apresentarse como liberal, suportando, se necessário, a existência de comunidades religiosas que não reconhecem a imperatividade de suas normas. Esses membros serão apresentados como cidadãos de uma sociedade civil, ambiente em que terão que seguir as leis estatais, caso contrário sofrerão com as sanções correspondentes, restando ao Estado, no entender de Hegel (1997), a observação dos direitos e deveres que possui para com esses tais indivíduos. Como observa Konzen (2014, p. 54),

[...] em Hegel, a doutrina de uma religião (Igreja) pode vir a ter que ceder em favor da do Estado, pois o Estado é aquele que sabe. Isto é, o Estado, segundo o conceito, é juiz das ações das Igrejas porque, para Hegel, no Estado a doutrina é racional. Assim, o Estado atua em plena consciência e é quem realmente constitui a organização da liberdade no nosso mundo. Ou seja, a supremacia do Estado se dá enquanto ele realiza soberanamente a razão. Segundo Hegel, "no Estado tudo é sólido e assegurado, é o reduto contra o arbítrio e a opinião positiva"; ora, justamente, por isso, "a religião como tal não deve ser aquilo que governa".

Fica evidenciado, nesse sentido, que Religião e Estado podem estar em acordo, ou em completa oposição. “A Igreja pode levar a diversidade dos dois domínios a mais irredutível oposição quando, com o pretexto de que possui o conteúdo absoluto da Religião, considera a realidade espiritual como assunto seu [...]" a figura do Estado seria apenas para fins externos, uma atividade meramente mecânica, ou como observa o próprio Hegel em sua obra, “profana”. (HEGEL, 1997, p. 221)

Há que se considerar conforme aduz Konzen (2014), no entanto, que para Hegel, a Religião poderá vir a ter que ceder em nome do Estado, visto que para o filósofo o Estado é aquele que sabe e se apresenta como juiz das doutrinas da Igreja em função do seu conhecimento racional. E partirá dele, considerando essa racionalidade, a construção dos ideais de liberdade que guiarão os sujeitos no interior da sociedade.

Portanto, no entender de Hegel '“[...] com uma religião da não-liberdade não é possível uma constituição racional, pois governo e povo precisam ter, reciprocamente, esta última garantia da vontade interna [...]" possível somente quando essa religião “[...] não se oponha à constituição do Estado racional." Seria uma espécie de meio termo entre Estado e Religião, 
sem que se tivesse que conviver com tiranias ou, também, com uma espécie de fanatismo religioso. (KONZEN, 2014, p. 54)

Assim sendo, o Estado tem um papel fundamental a cumprir na obra de Hegel à medida que seria sua obrigação “[...] 'conceder à comunidade toda a sua assistência para seus fins religiosos e de lhe garantir proteção,' pois o Estado deve promover a liberdade, inclusive, a religiosa." Fica evidenciado, ainda, que tanto a Religião como o Estado "[...] ocupam lugares de capital importância na vida humana. Mas, as autoridades estatais e as religiosas devem representar e secundar as aspirações de seu povo e se manter dentro dos limites de suas competências." (KONZEN, 2014, p. 54)

Ao finalizar o parágrafo 270 de sua obra, Hegel ainda coloca que essa separação entre Estado e Igreja possibilitará que esse atinja um pensamento universal racional e reconheça a sua verdadeira tarefa existencial. Mas a tarefa do Estado não estaria completamente independente do que fora colocado para a Religião, visto que ambos deveriam participar da construção de uma sociedade justa, e aparecerem como representados na Constituição estatal, fruto do espírito do povo. Seria uma espécie de busca pelo bem comum que se expressa nas leis estatais e que vincula todas as instituições a observaram o principio que guiará o Estado e suas instituições, qual seja, o princípio da liberdade.

O princípio da liberdade, além de ser um guia para as instituições estatais, também servirá como elemento vital para todos os indivíduos considerados pertencentes a uma sociedade serem reconhecimento enquanto tal. A realização da liberdade, no entender de Honneth (2007), só poderá ocorrer na intersubjetividade, nas instituições, estando sempre condicionada a interação entre sujeitos. Nessa interação social o indivíduos adquire dignidade frente aos demais e também frente ao próprio Estado, o que faz com que suas atitudes sejam validadas universalmente e tenha seus direitos e liberdades individuais garantidos.

\section{O Estado como locus para concretização da ideia de liberdade em Hegel}

Em sua obra Filosofia do Direito ${ }^{2}$, Hegel se propõe a construir um sistema filosófico do direito que tem como princípio fundador e orientador de suas análises a ideia da liberdade. Porque ciência filosófica do direito e não ciência do direito? A razão estaria no fato de que a

\footnotetext{
${ }^{2}$ Para John Rawls (2005. p. 376, grifo do autor), "Essa obra encerra sua filosofia moral e sua ideia distintamente institucional de vida ética (Sittlichkeit), e explica como ela se vincula com sua visão das pessoas como enraizadas no sistema de instituições políticas e sociais sob o qual vivem e são moldadas por esse sistema. Verdadeiro metafísico, ele acredita que a realidade é plenamente inteligível - o que é uma tese do idealismo absoluto - e, portanto, tem de encaixar-se nas ideias e conceitos de um sistema categórico razoável e coerente. Esse sistema é exposto passo a passo na Ciência da Lógica (1812-1816).”
} 
primeira possibilitaria a realização plena da ideia de liberdade, ampliando o campo de abrangência do direito de maneira a "expor o fio condutor da lógica interna das estruturas jurídicas enquanto realizações do Conceito de direito.” (WEBER, 1993, p. 46)

Para explicar como a liberdade se realiza no direito, Hegel faz uso do seu método dialético como forma de explicitar como se dá o funcionamento do sistema. Sempre considerando que "a ideia da liberdade a ser concretizada pelo conceito do direito é fornecida pela filosofia." Ou seja, ela já estaria dada "[...] não podendo mais ser questionada quanto à sua validade, na exposição de suas estruturas. Ela já se encontra na Ciência da Lógica e está, assim, fora da ciência do direito e é pressuposta [...]" (WEBER, 1993, p. 48)

A lógica teria como princípio, segundo Hegel, “[...] o ser, que desemboca na essência e finaliza no conceito. O ser é o indeterminado, sem forma ou conteúdo, porém, ao mesmo tempo, é toda determinação. Se o ser é nada, então ele é algo [...]" que pode se determinar. Todo esse movimento ocorre a partir do "movimento conceitual de opostos", ou seja, alcançando o conceito se chegaria novamente ao mais imediato, puro ser, indeterminado. Esse movimento circular, que parece não se saber onde estará seu início e seu fim, é o próprio movimento dialético, manifestação da essência. Ou seja, "a pura essência, conteúdo da lógica, quando exposta conceitualmente, movimenta-se dialeticamente; o movimento da essência é o mesmo do pensamento. A essência do pensamento é a essência dos objetos [...]” (STEIN, 2002, p. 79)

Nesse sentido para Stein $(2002,79-82)$, pode-se conceber o conceito como a "culminância da lógica, enquanto esclarecimento conceitual e movimento do pensamento." Ele seria "a visão do processo inteiro, que leva do ser determinado à união de todas as determinações." Ele é o absoluto pelo fato de carregar consigo todos os estágios que compõem a realidade.

Assim sendo, o método dialético que possibilita a explicação do sistema, seria desenvolvido da seguinte forma: "A tese (afirmação imediata) se encontra mediada (superada e guardada) na síntese, porque passou por um estágio intermediário, isto é, a negação ou antíteses." Assim, o sistema recomeça, encontrando na síntese final, "[...] a perfeição de todos os momentos anteriores percorridos, como suprimidos, guardados e superados." (WEBER, 1993, p. 42)

Para tanto, o início da compreensão sobre a realidade e o direito, pressupõe a noção de que a vontade, enquanto suprema manifestação da liberdade se manifesta inicialmente por meio do pensamento, que é livre. Para Hegel, não haveria vontade sem pensamento livre. "A 
raiz da verdadeira liberdade funda-se no pensamento, pois a idéia da liberdade é fundamentalmente pensamento. Sua realização é a sua autodeterminação [...]” Assim, "é pelo pensamento que se capta o universal, uma vez que pensar algo significa universalizá-lo, e, a partir de então, pode-se estabelecê-lo como meta ou objetivo a ser alcançado." (WEBER, 1993, p. 49) ${ }^{3}$

\section{Conforme o próprio Hegel argumenta no $§ 4$, da Filosofia do Direito,}

O domínio do direito é o espírito em geral, e sua base própria e ponto de partida é a vontade livre, de sorte que a liberdade constitui sua substância e sua determinação; o sistema do direito é o reino da liberdade realizada, o mundo do espírito que se manifesta como uma segunda natureza a partir de si mesmo.

Fica evidente nesse parágrafo que Hegel (1997, p. 47- 48) tem uma preocupação em demonstrar a origem das vontades humanas, e como a liberdade irá se realizar, visto que para ele, a vontade contém "o elemento da pura indeterminação ou da pura reflexão do $\mathrm{Eu}^{4}$ em si mesmo, em que se esvai toda limitação, todo conteúdo determinado imediatamente pela natureza, necessidades, desejos e instintos [...]” Ainda, “[...] contém a infinitude ilimitada da abstração ou universalidade absolutas, o puro pensamento em si mesmo."

Assim, a vontade livre é a autodeterminação do Eu. Como o próprio Hegel (apud RAWLS, 2005, p. 385) manifesta, "A vontade livre é a vontade que quer a si mesma como vontade livre." É a possibilidade que o ser humano possui de liberta-se e tornar-se completamente, tornar-se vazio, "pensamento puro da vontade sobre si mesma". Ao regressar o Eu se determina, e dá a si mesmo "conteúdo e objeto". Ou seja, "o conteúdo e o objeto da vontade são refletidos de volta nela e, dessa maneira, trazidos à universalidade. Isso é, como diz Hegel, individualidade."

Para Hegel, a realização da vontade inclui decisão e, como tal, uma vontade só se põe como vontade de um indivíduo. Uma vontade, que não se decide por algo, não é

\footnotetext{
${ }^{3}$ Conforme Weber (1993. p. 49, grifo do autor), "Para elucidar melhor a pressuposição da idéia da liberdade, na Filosofia do Direito, temos que recorrer à Enciclopédia das Ciências Filosóficas, mais precisamente, à parte final do espírito subjetivo, onde Hegel se refere ao objeto de estudo da psicologia. Nela é tratada propriamente a cognoscibilidade do espírito subjetivo. É através da análise do espírito teórico e do espírito prático que se chega ao espírito livre. No espírito prático, aparece o pensamento (espírito teórico) na forma de vontade, cuja suprema manifestação é a liberdade. O espírito teórico manifesta-se (objetiva-se) como vontade livre, que é o ponto de partida e o âmbito do direito.”

${ }^{4}$ Para Hegel (1997. p. 48), "O Eu é, principalmente, a passagem da indeterminação indiferenciada para a diferenciação, isto é, a delimitação e o estabelecimento de uma determinação que dá a sua caracterização um conteúdo e um objeto. Esse conteúdo pode ser dado pela natureza, ou ser engendrado a partir do conceito do espírito. Assim, o Eu, com esta afirmação de si mesmo como determinado, entra na existência em geral; é este o momento absoluto da finitude e da individualização do Eu."
} 
real. Ao decidir-se, porém, a vontade se limita. A possibilidade de determinação não significa ainda a sua realidade. Mas, ao determinar-se, a vontade entra numa contradição. Enquanto forma, ela é infinita; enquanto conteúdo, no entanto, é finita. Acontece que a vontade, enquanto formalmente infinita, não pode ser separada do conteúdo. Quanto a este, existe a possibilidade de escolha. O conteúdo da autodeterminação é, pois, finito. (WEBER, 1993, p. 54-55)

No entanto, como observa Hegel (1997, p. 54), o arbítrio não representa a total liberdade de escolha, a realização da vontade individual, em razão de que para se realizar ele sempre dependerá da contingência, ela sempre será parte do seu conteúdo. Segundo ele, “o homem comum se crê livre, quando lhe é permitido atuar arbitrariamente, mas é precisamente no arbítrio que radica a sua falta de liberdade."

Cabe referir, que a definição de vontade livre, proposta por Hegel, não representa a noção de uma vontade que apenas estaria movida por seus desejos e impulsos individuais. Mas ela é a vontade que "quer o que é próprio de uma vontade livre", ou seja, não se limitaria a um querer sem razão. A manifestação da vontade livre seria consciente do seu estar no mundo, consciente das instituições sociais que quer para garantida a liberdade. É a superação de qualquer forma de pensamento que privilegie as vontades individuais, mas é sim a exaltação da própria história humana. (RAWLS, 2005, p. 385)

É na Filosofia do Direito que se encontram os desdobramentos do conceito de vontade livre, visto que como princípio fundador, ele precisa ser desdobrado tendo em vista a sua abstratividade inicial, mesmo sendo possível antever no fim o próprio começo como superado e guardado, bem como o fim no próprio começo, de forma antecipada, mas ainda puro/indeterminado/imediato. "É essa dialética da necessidade e da contingência que mantém um nexo necessário, imanente ao sistema hegeliano, conforme se pretende demonstrar, e que dificulta o acréscimo de algo totalmente novo ao processo de determinação da ideia." (WEBER, 1993, p. 63)

Conforme Weber (1993, p. 63), para se realizar, a vontade livre irá compreender os seguintes três estágios: 1) Direito abstrato; 2) Moralidade; 3) Eticidade, compreendendo os momentos de realização da liberdade, quais sejam: a) abstrato; b) subjetivo; c) objetivo. "A eticidade é o espaço fundamental no qual as outras partes encontram justificação última." Isso significa que "o que numa fase se encontra como último, é a razão e verdadeira explicação do que antecede." Mas resta dizer que é somente no Estado que a liberdade encontrará sua plena realização.

É apenas no interior de um mundo social racional (razoável), um mundo que, pela estrutura das suas instituições, garanta nossa liberdade, que podemos conduzir nossas vidas plenamente racionais e boas. E embora nenhum mundo social possa 
garantir nossa felicidade, é apenas no interior desse mundo que a plena felicidade pode ser alcançada. [...] o papel da filosofia política, como Hegel a vê, é apreender o mundo social no pensamento e expressá-lo e uma forma na qual o possa ver como racional. Quando em nossas reflexões compreendemos nosso mundo social como algo que expressa nossa liberdade e nos capacita a alcançá-la à medida que conduzimos nossa vida diária, reconciliamo-nos com ele. (RAWLS, 2005, p. 378379)

Cabe aqui uma manifestação quanto à noção de reconciliação, apresentada na obra de Rawls (2005, p. 378), e que parece colaborar com o que fora dito até agora. Para ele, a noção de reconciliação é a "[...] percepção de nosso mundo social como uma forma de vida em instituições políticas e sociais que realiza nossa essência - isto é, a base da nossa dignidade como pessoas livres."

Diante disso, a '[...] a liberdade consiste em 'querer o universal', uma vez que agir arbitrariamente implica a 'falta de liberdade'. Mas querer o racional significa não agir como indivíduo particular e, sim, de acordo com o 'conceito do ético';" (universal). (WEBER, 1993, p. 56)

Para tanto, a liberdade apresenta-se como um conceito absoluto em Hegel, uma espécie de autoconsciência que se efetiva no conteúdo da sua vontade. A ideia é evidenciar a existência da relação entre querer e saber, e que esse encontro é externado através de uma autoconsciência, que resulta numa verdadeira efetivação da liberdade no campo da eticidade presente no sistema hegeliano.

Ao longo de sua construção teórica, Hegel explana que as históricas formas pelas quais já se apresentou a ideia de liberdade determinaram-se, também, pela concretização no mundo. Ao longo do tempo, estas concretizações apareceram como parâmetros comparativos de avaliação do grau de desenvolvimento da noção de liberdade.

Somente pelo método dialético seria possível a compreensão das três dimensões pelas quais passa a vontade livre até se efetivar plenamente como conceito, sempre considerando que a concretização da ideia de liberdade só acontecerá no âmbito do Estado. Cabe, a partir de agora, uma análise, mesmo que breve, das três etapas pelas quais passa a liberdade até concretizar-se.

Primeiramente, tomar-se-á por reflexão a noção de Direito Abstrato apresentada por Hegel, que compreenderia " [...] as formas concretas e imediatas da realização da ideia da liberdade, que é o fio condutor do direito. [...] Trata da estrutura racional das formas imediatas da vontade livre, ao nível das instituições jurídicas." Ela corresponderia à forma mais imediata de manifestação da vontade. Nesse sentido, o "direito abstrato pode ser chamado de 
'lógica do ser' do direito, uma vez que expressa a imediatidade da realização da ideia de liberdade." (WEBER, 1993, p. 63-64)

\begin{abstract}
O domínio do direito é o espírito em geral, e sua base própria e ponto de partida é a vontade livre, de sorte que a liberdade constitui sua substância e sua determinação; o sistema do direito é o reino da liberdade realizada, o mundo do espírito que se manifesta como uma segunda natureza a partir de si mesmo. (HEGEL, 1997, p. 46)
\end{abstract}

Nessa perspectiva, o direito abstrato apresenta as formas mais imediatas de percepção do direito, ainda indeterminadas, sem que nesse momento possa se falar em mediação por parte das instituições sociais. Ele é a representação das esferas privadas, mais íntimas, ocorrendo no âmbito do privado, "nas relações interpessoais".

No Direito Abstrato, os sujeitos são apenas portadores de direitos não havendo ainda reconhecimento recíproco. É nesse momento que Hegel apresenta a noção de pessoa de direito, que compreende a capacidade jurídica dada a cada sujeito concebendo os mesmo como portadores tanto de direitos quanto de deveres, ou seja, é o reconhecimento jurídico da noção de cidadão que se plenifica na maioridade dos indivíduos.

Para tanto, há uma diferença entre ser sujeito e ser pessoa em Hegel e essa diferença se expressa

[...] pelo fato de que cada homem, enquanto ser vivo é sujeito, mas, como tal, esse é somente a possibilidade de ser pessoa. O indivíduo que age deve ser reconhecido como pessoa do direito pela sua capacidade legal. $\mathrm{O}$ ser-pessoa implica um processo de conquistas, que culmina no Estado; ou seja, quando o indivíduo passa a ser cidadão do Estado. É no ato de posse de um objeto natural que o homem natural se torna pessoa; é a afirmação da individualidade. (WEBER, 1993, p. 66)

A moralidade, enquanto núcleo da vontade subjetiva seria um passo a diante, na perspectiva de Hegel. Ela representaria "a internalização do princípio da liberdade a ser respeitado em relação a todo o agir social." Nesse sentido, o sujeito moral sempre é "subjetividade universal". A moralidade representa o reconhecimento dos indivíduos como sujeitos, "uma vez que todos temos fins e quaremos que eles sejam atingidos, temos que procurar uma coincidência com a subjetividade dos outros.” (WEBER, 1993, p. 66)

Por tal razão, no entender de Weber (1993, p. 80-81), a moralidade representa toda a fundamentação do direito abstrato, ou seja, esse se encontra superado e guardado na moralidade, que avança em relação aquele, pelo fato de que há, a partir de agora, "[...] o reconhecimento subjetivo da liberdade como princípio universal." Tal afirmação possibilita 
certa garantia perante o acordo. "Em vez da noção de 'pessoa do direito', temos, agora, a noção de 'sujeito da moralidade' ou 'direito da vontade subjetiva'."

Percorrendo agora a esfera da eticidade, e tendo a moralidade como superada e guardada, há a necessidade de compreender que estamos diante das limitações impostas pelas instituições sociais. Assim, a superação das vontades puramente naturais das vontades mais imediatas impede o meu agir por meio da minha vontade natural.

A partir de agora, o sujeito encontra-se mediado, ou como alguns autores definem, aparece nesse momento à noção de vontade substancial. "A eticidade tem a função de tornar compatíveis as formas imediatas e externas do direito abstrato, por um lado, e a moralidade subjetiva, por outro.” Para que efetivamente isso se realize, “[...] terá que sintetizá-las num momento superior, isto é, a eticidade deve incluir como superados e guardados os momentos anteriores." (WEBER, 1993, p. 96)

É na eticidade, que se encontram as determinações objetivas e a mediação social da liberdade. Tem um conteúdo ético (conteúdo fixo), que se situa num nível superior ao das opiniões subjetivas: "as instituições e leis existentes em si e para si." (HEGEL, 1997, p. 149)

A noção de eticidade atualiza-se diante da unificação da subjetividade moral e a objetividade do direito, expressando claramente o movimento realizado pela liberdade enquanto substância. Com isso, o conceito de liberdade necessita ser revisitado no âmbito da eticidade, visto que ele representa a afirmação dos direitos civis dos cidadãos de um Estado. Isso acontece a partir do momento em que os indivíduos tomam consciência de si e da sua importância na história.

A eticidade também pode ser entendida "como a identidade do bem e da vontade subjetiva, [...] é o campo da moralidade social." É o momento em que “o indivíduo se libera de si para realizar-se plenamente na comunidade. É o âmbito dos deveres éticos, que são determinações objetivas do dever para com as outras pessoas.” (WEBER, 1993, p. 95)

Ainda, nessa mesma perspectiva, a eticidade preocupa-se com a ideia de liberdade que agora irá se desenvolver no plano da objetividade, ou seja, no espaço da comunidade e das instituições sociais. No entendimento hegeliano do processo de realização da ideia de liberdade resulta o surgimento do espírito, o qual pode ser representado pelas instituições sociais, pelas regras do dever ser, pelas normas morais e políticas, presentes em determinadas sociedades ao longo história.

Tendo a história como o lugar da realização do absoluto, conquista da sua identidade e diferenciação de si mesmo, é também nesse momento que, com a aparição do espírito, se 
determinam as mais diversas acepções da ideia de liberdade. Em sendo o espírito a própria liberdade, esse vai se desenvolvendo ao longo da história de maneira progressiva

No $§ 142$ da Filosofia do Direito, assim se manifesta Hegel (1997, p. 149):

\begin{abstract}
A eticidade é a ideia da liberdade, como bem vivente, que tem na consciência de si o seu saber e o ser querer e que, por meio de sua ação, tem a sua realidade. Esta ação tem o seu fundamento em si e para si, e a sua finalidade motora na existência ética objetiva. É o conceito da liberdade convertido em mundo real e que adquiriu a natureza da consciência de si.
\end{abstract}

Seria na eticidade que o sujeito entenderia as aproximações existentes entre a vontade universal a esfera particular, bem como, teria consciência de que no Estado ele estaria diante tanto de deveres quanto de direitos. Ou seja, só se tem direitos à medida que se tem deveres

Para Hegel (apud KONZEN, 2014, p. 51), “o Estado sabe o que ele quer, e o sabe em sua universalidade, enquanto algo pensado; e por causa disso, ele atua e age segundo fins conscientes, segundo princípios conhecidos e segundo leis que não são apenas em si." Segundo o referido autor, as ações do Estado "[...] se vinculam com as circunstâncias e as relações presentes, ele atua e age segundo o conhecimento determinado das mesmas.

O Estado preocupa-se, de forma objetiva, com seus fins e busca concretizar seus princípios de maneira a promover a verdade. É missão do Estado, “[...] proteger e assegurar a vida, a propriedade e o livre-arbítrio de cada um, na medida em que isso não lesa a vida, a propriedade e o livre-arbítrio de outro. O Estado aparece então como meio para suprir as necessidades;" (HEGEL, 1997, p. 222)

Assim sendo, "o Estado aparece como instância necessária, situada acima dos interesses corporativos, procurando preservar a universalidade. Constituído de regras bem definidas, será capaz de integrar os interesses particulares com os da coletividade." Isso representa a sua própria essência. (WEBER, 1993, p. 133)

Esse seria o momento de plena realização da liberdade, do seu reconhecimento e consciência de si mesma. A passagem da moralidade para a eticidade representa o passar de um ser moral para um dever-ser ético, ou seja, a síntese final no absoluto. O Estado seria o espírito objetivo. E, em sendo parte dele, o indivíduo teria "objetividade, verdade e eticidade." (WEBER, 1993, p. 135). A realização efetiva da eticidade só se daria no Estado, segundo Hegel

\title{
Considerações Finais
}


O presente estudo teve como objetivo estudar a relação entre Estado e Religião a partir da obra Filosofia do Direito de Hegel, e nessa perspectiva compreender como a questão da liberdade estaria diretamente relacionada com a posição ocupada pelo indivíduo em sociedade. Analisou-se o parágrafo 270 da referida obra de Hegel, no qual o autor desenvolve argumentos e aponta quais seriam as condições para estabelecer uma certa harmonia entre as duas instituições a fim de se criar um Estado da liberdade, bem como o desenvolvimento de um pensamento universal racional.

Relativo a liberdade, o próprio autor fundamenta que essa não ocorre de forma imediata, uma vez que mediada, passará por fases: primeiramente na Família, logo após na Sociedade Civil (corporações) e, por fim, no Estado. Somente nesse último estágio, o status individual/particular e subjetivo estaria superado e guardado no status objetivo/universal e necessário. O Estado seria, assim, a própria determinação do conceito de liberdade resultante do processo histórico.

Para tanto, segundo Hegel, somente no Estado o sujeito se reconhece como livre. Nele também, sua liberdade é reconhecida no momento que identifica as leis e os ideais do próprio Estado ao qual está inserido. É uma espécie de libertação dos seus instintos e das suas vontades mais individuais e imediatas (puras), ou da subjetividade indeterminada. Essa necessidade de limitações faz com que a liberdade se realize da maneira mais adequada oportunizando uma convivência satisfatória e possível na esfera estatal.

\section{Referências}

HEGEL, Georg Wilhelm Friedrich. Princípios da Filosofia do Direito. Tradução de Norberto de Paula Lima. 2. ed. São Paulo: Ícone, 1997.

Enciclopédia das Ciências Filosóficas em epítome. Tradução de Arthur Mourão. Edições 70, Lisboa, Portugal. 1969. Volume 3.

HONNETH, Axel. Sofrimento de indeterminação: uma reatualização da Filosofia do Direito em Hegel. Tradução de Rúrion Soares Melo. São Paulo: Singular/Esfera Pública, 2007.

KONZEN. Paulo Roberto. A relação entre Estado e Religião em Hegel. In Revista Dialectus. Ano 2. N. 4. Ceará: UFC. Janeiro-Junho 2014. p. 39-62.

RAWLS, John. História da filosofia moral. Tradução de Ana Aguiar Contrim. São Paulo: Martins Fontes, 2005.

WEBER, Thadeu. Hegel: Liberdade, Estado e História. Petrópolis: Ed. Vozes, 1993. 


\section{Sobre os autores:}

Anna Paula Bagetti Zeifert é Doutoranda em Filosofia, Área de Concentração Ética e Filosofia Política, no Programa de Pós-graduação em Filosofia da Pontifícia Universidade Católica do Rio Grande do Sul (PUC/RS). Professora do Departamento de Ciências Jurídicas e Sociais (UNIJUÍ/RS). Endereço eletrônico: annazeifert@ yahoo.com.br

Gabriel Maçalai é Bacharel em Teologia pelo Centro Universitário de Maringá (UNICESUMAR/PR), bacharelando em Direito pela Universidade Regional do Noroeste do Estado do Rio Grande do Sul (UNIJUÍ/RS) e licenciando em Filosofia pela Faculdade Entre Rios do Piauí (FAERPI/PI). Endereço eletrônico: diac.gabrielmacalai@ gmail.com 